\title{
Promoting cycling: development aspects in two different cities, Copenhagen and Patras
}

\author{
N. Tsakas ${ }^{1}$, E. Matsoukis ${ }^{1} \&$ I. M. Bernhoft ${ }^{2}$ \\ ${ }^{1}$ Transport \& Traffic Engineering Study Unit, \\ Department of Civil Engineering, University of Patras, Greece \\ ${ }^{2}$ Department of Transport, Technical University of Denmark, Denmark
}

\begin{abstract}
The problems caused by the extended use of private motor vehicles, tend to prove that it is indispensable to turn the attention to alternative, although vulnerable, transport modes. In order to encourage citizens to change their habits, appropriate conditions must be provided. In some European places, such as Copenhagen, Denmark, the conditions are already there and, by these, a high level of acceptance from the citizens is achieved. At the same time, in some other European cities, like Patras, Greece, conditions that encourage citizens to cycle or to walk, simply do not exist. The purpose of this paper is to recommend proposals for making Patras more bicycle friendly, based on the results of Copenhagen. A survey was carried out in Copenhagen (the so-called bicycle account), which revealed who the potential cyclists are, and what is the experience with cycle facilities. A multinomial logit model was then run, using as explanatory variables various personal characteristics, and the preferred mode of transport for different types of citizens was predicted. The results of this survey revealed the population groups that tend to prefer cycling and therefore constitute target groups for the future promotion of cycling. The existing situation for cyclists in Patras, Greece can be described as an absence of adequate facilities. A plan aiming at establishing bicycle tracks in a route connecting the city center to the University area was then proposed, together with the implementation of some other measures - on the basis of the Copenhagen experience - that assure the wide introduction of cycling in the city. The paper finally provides (i) useful guidelines regarding the factors that affect cycling conditions in Copenhagen and (ii) the plan for promoting cycling in Patras.
\end{abstract}

Keywords: vulnerable transport modes, bicycle, mode choice, multinomial logit model, bicycling facilities, Copenhagen, Patras. 


\section{Introduction}

It is worldwide accepted, that the transport habits of citizens in urban areas must change. One solution proposed is the substitution of motor vehicles by vulnerable transport modes, such as the BICYCLE. The city planners, in most cases, propose various methods to promote cycling in the urban environment (McClintock [7], Tolley [10], Buehler and Pucher [2]).

As an introduction to the present work, the existing cycling conditions in the city of Copenhagen, Denmark are examined. Copenhagen has one of the most extended and well-used network of bicycle paths worldwide. Based on the Bicycle Account (City of Copenhagen [3] - see also section 2.1), the total length of the cycle paths was found to be 388 kilometers $(\mathrm{km})$, consisting of $332 \mathrm{~km}$ cycle tracks, $17 \mathrm{~km}$ cycle lanes and $39 \mathrm{~km}$ green cycle routes. The Cycle Policy (City of Copenhagen [4]) is predicting a continuous improvement for cycling facilities in the forthcoming years. The cycle tracks are paths that are restricted to cycling and that are separated from the road sections used by cars. Other facilities are also implemented, such as bicycle parking, separate traffic signals for bicycles and bicycle transport in the public means of transport.

The role of education is crucial. The citizens of Copenhagen are well trained from their young age to behave appropriately as road users. There is a whole education plan beginning from the age of 3, with informative toys. At the school age, the cyclists are trained in fulfilling some necessary cycling skills, like bicycle balance and control, as well as signal apprehension, in order to communicate with other road users. Also, they are trained to behave with responsibility, which means (i) to use helmets (ii) not to cycle under the influence of alcohol and (iii) to keep their bicycle well maintained (use of lights etc.). Furthermore, they learn to respect the traffic rules that refer to every road user, and especially those to cyclists. These include the traffic signals operation, the use of the correct traffic lanes for bicycles and the apprehension of priority rules at junctions. Finally, they learn that safety is the major priority in transport; this should be the primary concern in their behavior. The latter implies high ability to react to external inconveniences, predictable riding and wearing visible clothing. Even more it refers to safer turnings, less risky movements and planning of trips through the safest possible route. The riding education continues after the end of the school years with public informative campaigns.

Another serious factor is the cyclists' exposure to danger. In order to make cyclists safer, Copenhagen has established separate traffic lights for the bicycles, "recessed stop lines" for cars, so that the drivers be aware of the cyclists that have stopped before the junctions, "blue lanes" through the junctions to make the cyclists more visible and traffic calming zones, where cycling and walking has higher priority than car driving.

Concluding, there are still measures to be taken to improve traffic conditions for cyclists. The extension of the connections to public transport, as well as the construction of modern protected storage facilities can make the bicycle a more attractive and competitive transport mode. 
In Patras, the bicycle is not realised as a considerable part of the traffic network. Its use is very limited and there is complete lack of infrastructure. Patras is the third biggest city of Greece, located in the western part of the country, around $220 \mathrm{~km}$ from Athens. The population of the city, based on the most recent censuses, is approximately 190.000 citizens; however, the wider Patras complex includes 350,000 inhabitants. Approximately 40.000 of them are students at a higher education level (either in the University or in the Technological Education Institution). The main economic activities of the city are related to the big harbor, which comprises the major gate of Greece to Italy and further to the Western Europe area. The harbor operation affects, in a considerable way, the traffic conditions of the city.

At present, the cycling level in the city is very low, despite the fact that the city lies on horizontal grounds, which usually favors cycling. However, during the last years, there has been an increasing effort to implement cycling in the city's road network; this is also the case for other middle-sized Greek cities (Vlastos and Birbili [12] and Vlastos et al. [13]).

\section{Characteristics of modal choice in Copenhagen}

An attempt to figure out the cycling habits and the behavior of the Copenhagen's citizens was made. This attempt was based on a statistical analysis, in which the participants were the citizens of Copenhagen that replied to the "Bicycle Account 2006" questionnaire. On the basis of these replies, several socio demographic characteristics were correlated to the preferred transport mode (three choices: bicycle, car or public transport). Similar surveys have been run during the past years (e.g. Hansen and Jovicic [6] and Vuk et al [14]). For carrying out this analysis, the theory of discrete choice models was used (Train [11] and Wooldridge [15]), and more specifically that of a multinomial logit model (McFadden and Train [8]) using the three previously mentioned choices.

\subsection{Aim, method and data analysis}

The effect of individual socio-demographic characteristics on traffic behavior was investigated (more specifically on the individual choice of transport mode). The aim was to determine the population groups that are more likely to prefer cycling. Thus, in the future, it would be possible to focus on some special promotional measures or provide some further incentives for those specific groups.

The data used in the analysis originated from the Municipality of Copenhagen's "Bicycle Account 2006" questionnaire. The sample was selected randomly from all citizens of Copenhagen Municipality and it consisted of 1002 people older than 16 years; 567 of the participants were women and 435 were men. Due to problems with missing and confusing values and in order to provide accuracy to the results, a revised sample was used, consisting of 846 of the participants who replied the whole questionnaire in an acceptable way. This reduction consists approximately $15 \%$ of the original sample (Allison [1]). The 
explanatory variables used were (i) several personal characteristics such as occupation, education, income, age, gender, children in the household and (ii) three additional variables: whether or not the persons have access to bicycle; whether or not the persons have access to car; and how often they walk for long distances. Based on the latter, the evaluated model could better fit to the existing observations. A non-linear model was used in order to estimate the attractiveness of cycling as the main mode of transport in urban areas, compared to other modes of transport. The underlying choice set is finite (bicycle, car, public transport), and thus it is suitable to apply discrete choice modelling. Moreover, a multinomial logit model, which fits well to this framework, was used, after ensuring that the relevant restrictions hold in the present occasion. In parallel, several tests were run to check the suitability of the explanatory variables (hypothesis test) and of the model (likelihood-ratio test for independence from irrelevant alternatives). The most tactile results were exported from the computation of the marginal effects of the explanatory variables on the choice probabilities. The marginal effects give the opportunity to proceed to more tactile results and bring out several proposals on which groups are more likely to be attracted and the ways by which this attempt should take place.

\subsection{Results}

The modal preference based on the level of education is presented in figure 1. The main notifications here are (i) citizens that have studied for more than five years in the university are characterized by a high preference towards cycling and (ii) primary school graduates are characterized by a high preference towards public means of transport.

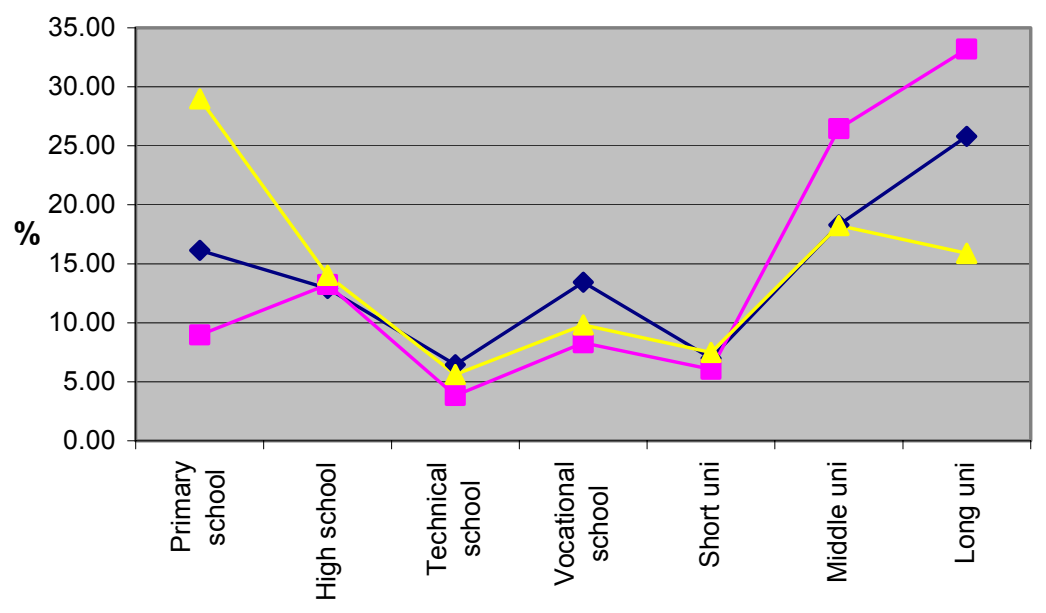

EDUCATION LEVEL

CAR - BICYCLE - - PUBLIC TRANSPORT

Figure 1: Preference of transport mode related to the level of education. 
The so-called Marginal Effects are the derivatives of the choice probabilities for each explanatory variable. The calculation of the derivatives provides the opportunity to identify the change in the probability that a participant chooses an alternative, for a unitary increase of an explanatory variable. Thus, it was possible to specify to what extent the probability of choosing each mode separately is affected. The most accurate method to test the marginal effects was to do it separately for each individual. In case of big samples however, this is difficult and inconvenient, so a useful way is to record the marginal effects averaged over the individuals. The sum of the derivatives must add up to zero, as a result of the requirement that the sum of the probabilities must add up to one. Given this fact, an improvement in the probability of an alternative is equal to the sum of the decreases in the other alternatives. The matrix of the Table 1 provides clear and visible results.

Table 1: $\quad$ Marginal effects of all the explanatory variables.

\begin{tabular}{|c|c|c|c|}
\hline VARIABLE & $\underline{\text { CAR }}$ & $\underline{\text { BICYCLE }}$ & $\underline{\text { PUBLIC TRANSPORT }}$ \\
\hline Access to bicycle & $-0,3393$ & $+0,7074$ & $-0,3679$ \\
\hline Access to car & $+0,4591$ & $-0,3001$ & $-0,1590$ \\
\hline Children & $-0,0270$ & $+0,0563$ & $-0,0293$ \\
\hline Occupation & $-0,0161$ & $+0,0087$ & $+0,0074$ \\
\hline Education level & $-0,0014$ & $+0,0214$ & $-0,0200$ \\
\hline Income & $+0,0183$ & $-0,0076$ & $-0,0107$ \\
\hline Age & $+0,0080$ & $-0,0482$ & $+0,0402$ \\
\hline Gender & $-0,0187$ & $-0,0317$ & $+0,0504$ \\
\hline Walking & $-0,0184$ & $+0,0137$ & $+0,0047$ \\
\hline
\end{tabular}

Firstly, the result on the factors access to bicycle and access to car can be noticed. As it was expected, these factors affect to a high positive degree the probabilities of bicycle and car use respectively. This notification is not worthy to be explained more, as the relation is obvious.

Secondly, the appearance of children under the age of sixteen years in the household, favors the use of bicycle. On the other hand the negative effect against the other modes of transport varies around the same level. In explaining, the participants that live with young children are either their sisters/brothers, or their parents, normally not exceeding the age of 55 years. This fact provides them with a natural condition that encourages sport and cycling. Additionally, parents tend to educate their children to cycle, so they try to behave as an example towards them.

Furthermore, the education level affects positively cycling. Citizens with longer education tend to prefer the bicycle compared to other modes. The higher the level of education, the more people understand the positive effects of cycling, both for the individual and for the environment. They seem to be more interested in health and environmental protection, than in speed and convenience as provided by the car. Higher income seems to act in the opposite way. People 
with high salaries seem to prefer the convenience of their car. The ability to cover easily the maintenance costs of their car, in addition to the flexibility and isolation that the car provides, are the main reasons for this tendency. Thus, it seems that uneducated rich people constitute a social group that is very unlikely to be attracted to cycling.

Another significant and rather expected result is that the increase in age discourages the decision of choosing the bicycle as the preferred mode of transport. This is an obvious remark, taking into account that the requirements of cycling are fitness and stamina. The encouraging element here is that older people turn more to the use of public transport and not to the use of the car. So, even if they do not improve their natural condition, at least they do not contribute to the environmental pollution.

The gender is a factor that favors the use of public transport by men. The higher interest of women in convenience, added to the - in any case - higher percentage of male drivers, gives the main explanation for these results.

Finally, citizens that are likely to walk frequently prefer more the bicycle and the public transport than the car. Many of the reasons previously mentioned can explain this result. Usually, people that prefer to walk care more about their health, which is an encouraging factor for cycling. Additionally, they tend to care less about convenience and speed during their trip, which also favors cycling and use of public transport. These citizens also seem to be more concerned about environmental protection.

\subsection{Policy implications}

The individual characteristics that determine the preferred transport mode for the citizens of Copenhagen were previously discussed. The model that was used did not provide complete information in order to define the behavior of each individual. Instead, it allowed the evaluation of the probability of each alternative to be chosen by a participant. Due to this fact, it was possible to predict the change of behavior, given a specific change of attributes and to predict some measures that could promote cycling and walking for specific social groups.

First of all, as it was previously mentioned, low income, young age and high level of education are three factors that encourage cycling. These characteristics define the profile of a university student. This in fact means that the university students are likely to be attracted to cycling even more than other population groups. In this direction several measures can be proposed, such as the improvement of cycling facilities inside the university campuses. Also, a discount in the price of bicycles for students would be a serious incentive to attract them.

Secondly, low income is not only a characteristic of the students. All low-paid employees would be more interested in cycling, if they perceive it as a mode that can provide efficient, fast, but mostly cheap transportation. There are various ways to promote this perception. e.g. lowering the maintenance cost for a bicycle because although it is much lower than that of a car, it is still considerable. While it seems at present unlikely to provide a free bicycle for each citizen interested, it 
would be possible to create specific places that could provide cheap service for simple bicycle damages. Even more, the so named "city bikes" (Vlastos and Birbili [12]), which provide transport almost for free, could be implemented in a more advanced level. Thirdly, another social group that could be attracted would be the families with young children. If parents want to make their children familiar to the bicycle, then they would also tend to use it themselves. Informative conferences about the positive effects of cycling could be organized at schools, not only meant for the pupils, but in particular for the parents. This way, more parents will learn to understand the positive effects of cycling and they will also transfer this attitude to their children. Even more, the supply of children's first bicycle for free can be a good incentive for both parents and children.

Finally, people who like to walk are also more likely to prefer cycling. This shows that they seem to understand the healthy effects of cycling and they perceive it as a nice way of exercise. This could be the main focus of a promotional effort. This effort should aim to make more people realize the importance of exercise in general, and apprehend cycling both as an effective method of training and as a healthy habit.

\section{Development of cycling in Patras, Greece}

In the previous section, it has been found that highly educated people are more likely to be attracted to bicycle than any other population group. This includes the university students. In the same time in Patras, the university students consist a considerable proportion of the whole population. Based on the above, a plan for the development of cycling in Patras aiming at this target group was developed and is presented in the continuation. This includes (i) a bicycle route connecting the University to the city center and (ii) an extended bicycling network inside the University area. Furthermore, some other measures and actions are proposed in order to promote cycling.

\subsection{A plan for the improvement of cycling conditions}

The first part of the bicycle plan for Patras includes designing of a bicycle route , which connects the university to the city center. One path for each direction of a road is proposed; the aim of the plan was not to propose a whole bicycle network for the city of Patras, but rather to introduce a bicycle corridor, mainly for the university students. The total length of the proposed route is approximately $10 \mathrm{~km}$. This bicycle route is depicted in Figure 2 (it includes the streets Panepistimiou, Kanellopoulou, Iroon Polytechneiou, Agiou Andreou).

As it can be seen, cyclists ride in both sides of the road, except for the part of the route which is included in Figure 3 where cyclists will be riding on two different streets, depending on the direction. A first matter regarding the implementation of the above plan is to check if the roads proposed are wide enough to accommodate the bicycle tracks. The restrictions and limitations described elsewhere (Vlastos and Birbili [12]) were taken into account. The latter mainly refer to the minimum road width, which is necessary to secure the 


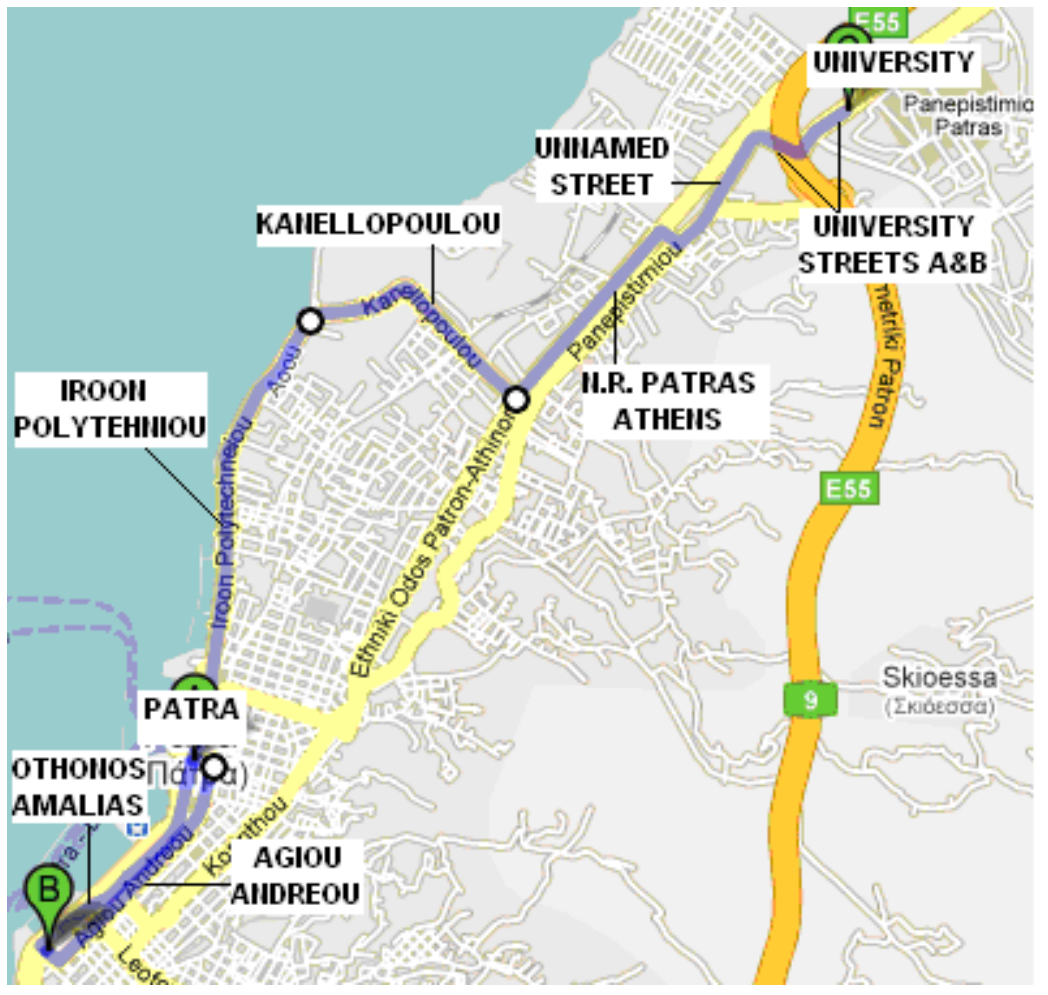

Figure 2: A complete overview of the bicycle route [http://maps.google.com/].

coexistence of bicycle and other transport modes (see table 2). In most cases, there will be enough space for the implementation of a bicycle track. However, along the part of the route where the two bicycling directions follow different streets, i.e. Othonos Amalias and Agiou Andreou streets (Figure 3), the need for space is not fulfilled, therefore an expansion of the roadway is necessary (see Table 2)

Next, the type of cycle path that would be used should be determined, as well as the specific measures to be enforced, in order to secure both regular traffic operation and safety for the cyclists. For this purpose examples from the observed situation in Copenhagen were used, as well as from other previous studies (ADONIS, Nilsson et al. [9]).

The lack of cycling culture in Patras has led to the proposal of bicycle tracks totally separated from car traffic. This combined to the limited space that was available, gave the following optimal solution: the establishment of bicycle tracks next to the roadway, but at a different level, that of the pavement. Moreover, in order to restrict citizens from parking on the bicycle tracks, cones could be used at the edges between the bicycle paths and the roadways. 


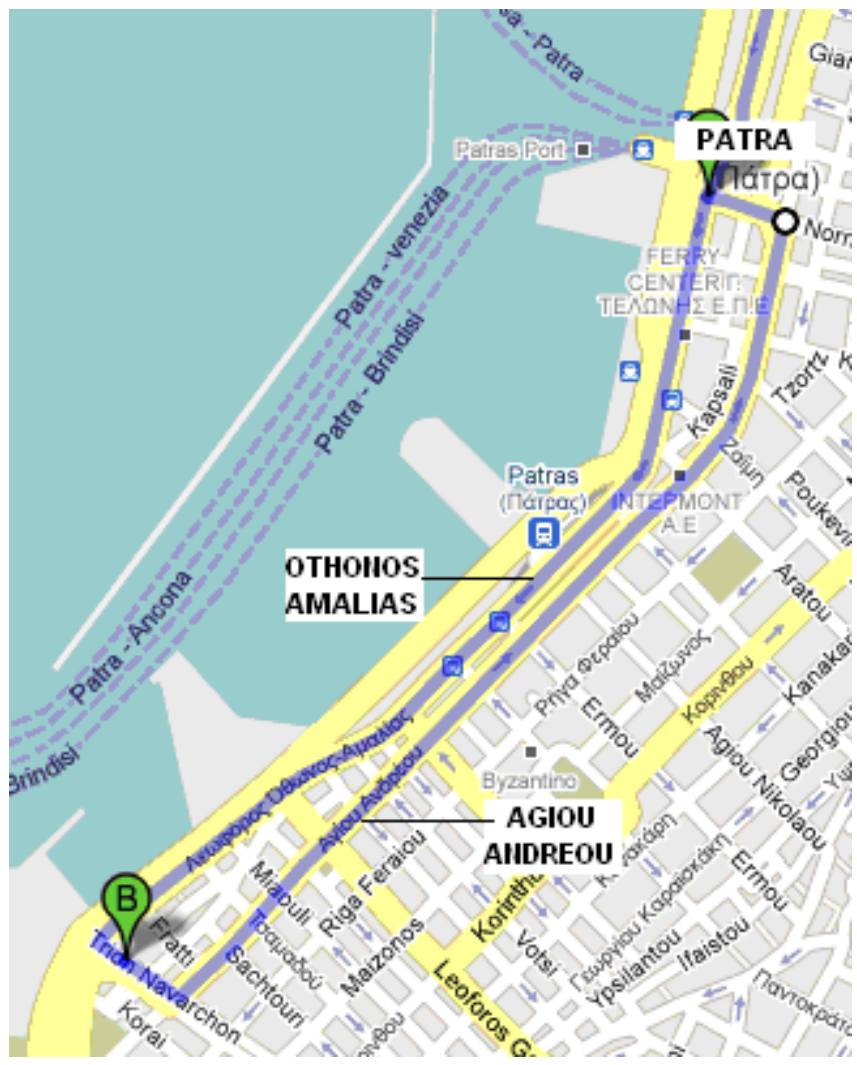

Figure 3: Part of the route where the two bicycling directions follow different streets [http://maps.google.com/].

The bicycle plan is not limited to the construction of bicycle tracks. Bicycle parking areas are proposed to be built along the route. These should be connected to the pavements along the route, to squares and to other specific locations. They should provide security, safety, convenience and flexibility, therefore they must be placed in visible areas. For the specific route under discussion, one bicycle parking is proposed for the university area, one for each of the train and bus stations and one for the most faraway point of the route. It is obvious that the above parking areas would provide accessibility to cyclists from many other parts of the city, thus making cycling more attractive and comfortable in general. Based on the example of Copenhagen, some other regulations are suggested to assist the acceptance of the bicycle presence in the traffic network. First, the passages for cyclists at junctions must be appropriately marked, so that the drivers would always be aware of the cyclists. Also, "recessed stop lines" for cars must be designed in every signalized intersection, in order to avoid accidents. 
Table 2: $\quad$ Characteristics of the road parts and comparison between required and existing widths for the establishment of bicycle lanes, based on the geometric standards (Vlastos and Birbili [12]).

\begin{tabular}{|c|c|c|c|c|c|c|}
\hline Road Part (Map) & $\begin{array}{c}\text { Car } \\
\text { Lanes }\end{array}$ & $\begin{array}{c}\text { Speed } \\
\text { Limit }\end{array}$ & $\begin{array}{c}\text { Lorries/ } \\
\text { Busses }\end{array}$ & $\begin{array}{c}\text { Parked } \\
\text { Cars }\end{array}$ & $\begin{array}{c}\text { Required } \\
\text { Width }\end{array}$ & $\begin{array}{c}\text { Existing } \\
\text { Width }\end{array}$ \\
\hline Othonos Amalias & 2 & 50 & YES & NO & 7,7 & 12 \\
\hline Agiou Andreou & 2 & 50 & YES & NO & 7,7 & 8 \\
\hline Iroon Polytehniou & 2 & 50 & YES & NO & 10,1 & 11,5 \\
\hline Kanellopoulou & 4 & 50 & YES & NO & 16,2 & 16 \\
\hline N.R.Patras-Athens & 4 & 50 & YES & NO & 18,2 & 18,5 \\
\hline Unnamed Street & 2 & 50 & YES & NO & 7,7 & 9,5 \\
\hline University Str. A & 4 & 50 & YES & NO & 17,5 & 17 \\
\hline University Str. B & 2 & 50 & NO & NO & 6,85 & 8,5 \\
\hline
\end{tabular}

The implementation of independent cycle routes is the most important part of the whole plan and would certainly create reactions. This part of the plan includes the prohibition of parking along the right side of the street. Also parking next to the track should be banned, because it will disturb the cyclists.

\subsection{Discussion of promotional measures}

The lack of "bicycle culture" and "bicycle education" consists a big problem, thus it is highly important to start promotional information and campaigns. It is obvious that the general public preference towards bicycle will not change from one day to another. It must be accepted that this is a procedure that will last for long time.

Finally, there are some other measures that could promote bicycle use, e.g. bicycle activities during the year (and ways of advertising them), the establishment of an official bicycle day and the distribution of leaflets focused on various road safety aspects (see Nilsson et al. [9]).

\section{Conclusion}

This paper provided results from a survey in Copenhagen, Denmark that give input to proposals for promoting cycling in Patras, Greece. At present, Copenhagen seems to be safer and friendlier for cyclists compared to Patras. The situation in Copenhagen, however, can still be improved, by focusing mostly on education, competitiveness and attractiveness of the bicycle as a transport mode.

In Patras, the lack of appropriate infrastructure and cycling education have been realized. A plan is proposed, which covers some of the cycling demands. Based on the results of the survey in Copenhagen, which revealed university students' preference towards cycling, this includes a bicycle track that connects the city's University to the city center. 
In general terms, it seems that the university students are the ideal population group for promoting cycling in places where this is not common. Additionally, other population groups may tend to cycle such as citizens with low income and families with children. Probably some extra incentives for poor people, such as cheap service, or cheap "city bikes" would be cost- effective regarding social benefits. As for parents, measures such as informative conferences and for children measures such as "the first bicycle for free" would be extremely efficient and beneficial towards bicycle promotion.

\section{References}

[1] Allison, P., Missing Data. Sage Publications, 2001.

[2] Buehler, R. \& Pucher, J., Making cycling Irresistible: Lessons from The Netherlands, Denmark and Germany. Transport Reviews v.28, Is.4, July 2008

[3] City of Copenhagen, Bicycle Account 2006. City of Copenhagen, Technical and Environmental Administration, Traffic Department, 2006

[4] City of Copenhagen, Cycle Policy 2002-2012. City of Copenhagen, Building and Construction Administration, Roads and Parks department, 2002.

[5] Gogola A. \& Vagiotas P., "Bicycle tracks network in Patras", Scientific Workshop for Public Transportation, Sustainable Mobility and Urban Development in the Greek cities of the region. TEE of western Greece, 2008.

[6] Hansen, C.O. \& Jovicic, G., The Orestad Traffic Passenger Demand Model. Transport and Traffic Conference in Aalborg, Denmark, 2001.

[7] McClintock, H., Planning for Cycling: Principles Practice and Solutions for Urban planners. Woodhead Publishing, 2002.

[8] McFadden, D. \& Train, K., Mixed MNL Models for Discrete Response, Journal of Applied Econometrics, 2000.

[9] Nilsson, P.K., Dijkstra, A., Levelt, P., Thomsen, J., Thorson, O., Severen, J.V. \& Laursen, J.G., ADONIS - Best practice to promote cycling and walking.

[10] Tolley, R., Sustainable Transport: Planning for walking and cycling. Woodhead Publishing, 2003.

[11] Train, K. Discrete Choice Methods with Simulation. Cambridge University Press, 2003.

[12] Vlastos Th., Birbili T., Developments and policies for introducing bicycle in a Greek city: investigation of the geometric standards on the basis of European experience. European Union, Greek Ministry of Transport, 2000.

[13] Vlastos, Th., Milakis, D., Athanasopoulos, K., The Research for Cycling in Greece. Methodology of Planning, Infrastructure Standards and a Typology of Design Solutions. Proceedings of the 15th International Velo-City Conference, Dublin (Ireland) 31 May - 3 June 2005, 2005.

[14] Vuk, G., Hansen, CO. \& Nielsen, OA., The Orestad Traffic Passenger Demand Model, Version 5.0. Aalborg University, 2006. 
298 The Sustainable City VI

[15] Wooldridge, J., Econometric Analysis of Cross Section and Panel Data. MIT Press, 2002.

[16] http://maps.google.com/ 